\title{
Study on the Difficulties and Countermeasures of the Migratory Bird Style for Health and Wellness Tourism Industry in Panxi Ethnic Areas
}

\author{
Chunqiu Luo \\ College of Socialist Theory and Education with Chinese Characteristics, Panzhihua University, \\ Panzhihua 617000, China; \\ E-mail:rexrex1985@126.com
}

Keywords: Panxi ethnic area; Health and wellness tourism; resource conditions; development pattern

Abstract: In view of the current situation of population aging in China, the state has proposed to strengthen the aging and social resources to develop the old-age industry, and pay attention to the health care of the elderly. In particular, the migration of elderly people from the north to the south or the central region has become a trend. This kind of pension system combining tourism and old-age care is called "Migratory Bird" recreation tourism. The Panxi ethnic area has the sunshine, air, landscape, fruits, culture and sports-based health and wellness tourism resources. The development of the "Migratory Bird" style of health and wellness tourism industry has very convenient resource conditions, and it is bound to become a local economic income pillar. In this regard, the paper, from the "one core, one axis and five plates" in Panxi area as the development space of health and wellness tourism resources, will analyze the tourism resources of Panxi from the three tourism product systems of recreation, health and wellness, develop strategies, summarize current development dilemmas, and find ecological security measures based on the development of health and wellness tourism resources.

\section{Introduction}

The Panxi Economic Zone is rich in natural resources and a unique climate, with great development value and development potential. Developing the characteristic economy of Panxi Economic Zone and striving to build the second-level economic growth pole of the province is the main goal of the development of Panxi Economic Zone in the new era. It is also the implementation of Sicilian's "multi-purpose and multi-word" support and the coordinated development strategy of the five economic zones. It is an important measure to fully transform the regional resource advantages into industrial advantages and ensure the healthy and sustainable development of the province's economy and society. Health and wellness Tourism organically integrates green industry with health industry. Through people and nature, it meets people's fundamental desires and basic demands for high-quality life such as body-building, beauty, nourishment, raising wisdom and raising heart. It is quickly interpreted as a national tourism [1-2]. 


\section{Advantages of Health and wellness tourism resources in Panxi area}

\subsection{Sunshine Health Resources Advantage}

The Panxi ethnic minority area is located at the junction of Sichuan, Yunnan and Guizhou provinces. It is a three-dimensional climate with the island-like southern subtropical zone as the base zone. The number of sunshine hours in Panxi can reach 2700 hours/year, and the frost-free period is more than 300 days. The average temperature in winter is $13-20{ }^{\circ} \mathrm{C}$, the average temperature in summer is $24.6-25.5^{\circ} \mathrm{C}$, and the average annual temperature is $20.3{ }^{\circ} \mathrm{C}$. Due to factors such as dryness, clear rainy season and relatively low relative humidity, the climate in Panxi area is characterized by warm winter sun and cool summer. The abundant sunshine resources throughout the year make it a strong contrast with the Sichuan Basin and the cities in Guizhou, which have a subtropical humid climate with a cloudy and rainy day. It is the region with the highest annual average temperature and total calories in Sichuan Province. It is the only one in Sichuan Province. A city without winter. Panxi's sunshine health tourism resources are very conducive to the treatment of various geriatric diseases, chronic diseases, reducing disease recurrence, and can meet the long-term needs of tourists from many regions [3].

\subsection{Air Health Resources Advantage}

According to the "Air Quality Report for May 2014 in the Cities of 21 Cities (States) of Sichuan Province", Panzhixi has the highest proportion of air quality compliance days in the eight key environmental protection cities, accounting for $35.48 \%$. According to the data of Panxi Environmental Protection Bureau, the average monthly air environmental quality compliance rate of the city in September 2014 was $100 \%$, and the monthly average concentration values of sulfur dioxide and fine particulate matter all met the secondary standard requirements of the new national environmental air quality standard. In 2015, Panxi's excellent air quality rate reached 98.9\%, ranking third in Sichuan after Kangding and Malcom.

\subsection{Advantages of Shanshuii Health and wellness Resources}

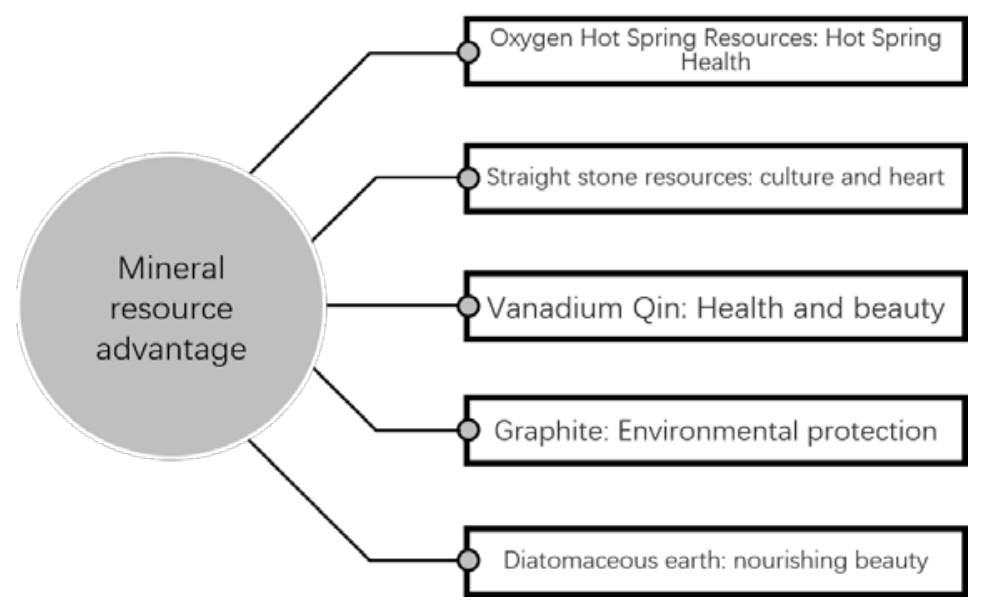

Fig. 1 Mineral resource advantage map

The Jinsha River, the Yabi River, the Anning River and its tributaries form a deep valley with dense water networks in the west of Panxi. The height difference between the mountains and the mountains is very high. The maximum height difference is 3259 meters. Ertan Hydropower Station, Tongzilin Power Station, Guanyin After the construction of the power station such as Yan, several 
high-level Pinghu landscapes were formed; the Jinsha River crossed the Hengduan Mountains and formed the well-known Panxi Rift Valley, which is comparable to the African Rift Valley. Panxi area is a key state-owned forest area in Sichuan and an important water source conservation and water and soil conservation area in the upper reaches of the Yangtze River. The city has a total of 559,900 hectares of forestry land, accounting for $75.1 \%$ of the total area, and the forest coverage rate is $60.03 \%$, which is close to 3 times the national average.

\subsection{Mineral health resources advantages}

The gemstone jewelry worn by people contains a lot of minerals that are good for human health. Geothermal hot springs are both water resources and mineral resources. Geothermal fluid, as a heat carrier medium, is of great value to human health. China's famous Health and wellness tourist resort Wudalianchi natural mineral water has been proven for many years to treat various diseases of the digestive system and other systems and skin. It can be seen that mineral resources have higher development value of Health and wellness tourism resources. According to the research needs, the author puts forward the concept of "mineral resources". That is, mineral resources that can be exploited in the natural environment or have a certain effect on human health and health based on regional geological conditions are called “mineral resources”.

\section{Demand Analysis of the Development of Health and wellness Tourism Resources in Panxi Ethnic Areas}

\subsection{Accelerating population aging and promoting the development of Health and wellness resources}

With the advent of China's aging society, the demand for health care and care for the elderly has become an important growth direction for China's Health and wellness tourism market, and the potential for the elderly to serve the consumer market is huge. In 2013, China's elderly population over 60 years old exceeded 200 million, and the aging level reached $14.8 \%$. It is estimated that by 2020, China's pension industry market will reach 5 trillion yuan. It can be seen that the market potential for the development of health care resources for the elderly groups is huge.

\subsection{Sub-health problems have intensified, and the development of Health and wellness and Health and wellness resources has been promoted}

Work and life pressures have gradually increased. China's sub-health population is huge, accelerating the health market demand, and the young and middle-aged sub-health market is gradually increasing. Nutrition, health care, leisure and health, fitness and recreation, and health management have become new highlights. The State Council has clearly stated that the total size of the health service industry will reach 8 trillion yuan by 2020, which means that the annual growth rate of China's medical and health service industry will reach at least $25 \%$ by 2020 , and the related health tourism will usher in long-term sustainability. The development of high prosperity.

\subsection{Leisure vacation and tourism complex tourism demand, drive the development of Health and wellness resources}

Panxi is located in the middle hub of Sichuan and Yunnan's two major tourist highlands. It is the ancient "Southern Silk Road" fortress. It is driven by the radiation of the Shangri-La Tourism Circle and the Chengdu-Chongqing City Circle. The tourist source market is vast. Panxi should actively 
meet the needs of national leisure vacations, promote the transformation of tourism products to tourism, leisure and vacation, meet diversified and multi-user tourism consumption needs, actively seize market space, and promote the development of Health and wellness resources.

\subsection{Winter sheltering needs, "Migratory bird" vacations promote the development of Health and wellness resources}

In China, Yunnan, Hainan, Guilin, Guangxi and other places have become popular destinations for winter tourism. Abroad, Australia, New Zealand and South Africa, Southeast Asia and other countries are popular choices for tourists. At present, the "migrant birds" who have gone to Panxi for the winter have already had a clear market share, and have shown a rapid growth trend, which has promoted the development of winter escaping resources.

\subsection{Avoid smog and promote the development of Health and wellness resources}

In recent years, smog in big cities has become more and more serious. Especially after the winter, there are frequent smog weather in North China and even across the country. The smog locks the city, bronchial diseases, respiratory diseases frequently occur, especially children and the elderly group become a concentrated group of respiratory diseases. The fresh air has become a luxury for the big city crowd. Health and wellness tourism destinations such as "hiding tour" and "washing lungs" have received great attention. In this season, it is precisely the best time for the sunshine resources in Panxi. The smog-stricken groups in Chengdu, Chongqing and other big cities closer to Panxi area have spawned the development of the Health and wellness resources of Panxi area.

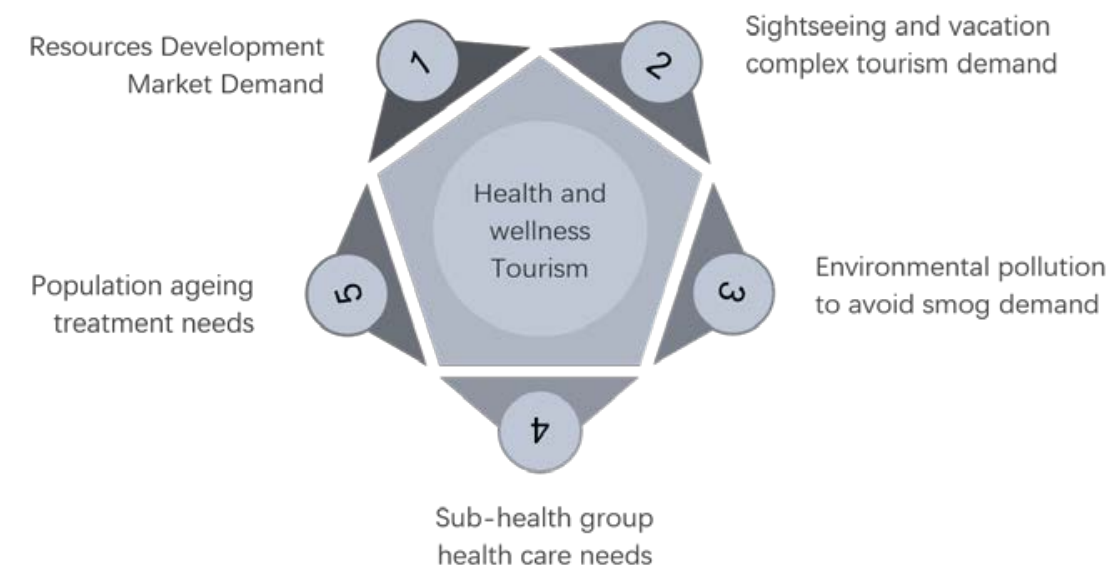

Fig.2 Schematic diagram of the source of demand for recreation and tourism resources

\section{The current development of the tourism industry in Panxi ethnic areas}

\subsection{Geographical location is remote, not well known}

The disadvantages of Sichuan forest health tourism in the initial stage are as follows: First, some forest areas are remote and the infrastructure is backward. Especially the state-owned forest farms are mostly located at the tails of high mountains, steep slopes and deep valleys. The cost of infrastructure construction is high. In addition, in recent years, the central and provincial finances have invested less in the construction of state-owned forest farms, and the infrastructure renovation has lagged behind, becoming the hardware constraint for the forestry transformation and development of forest recreation and tourism. Second, homogenization competition is serious. The 
neighboring nature reserves in the region lack features and coordination is not enough. There are price discounts to attract customers, fail to achieve differentiation, integrated development, and lack of brand. Third, there is a shortage of professionals. As a new tourism industry, the forestry and recreation tourism industry's knowledge structure and academic level cannot meet the needs of the current development of Health and wellness tourism. Fourth, the concept and concept are not well understood. At present, there is a lack of understanding of the concept of forest health, inadequate understanding of the effectiveness of forests, and neglect of the experience of forest health. Fifth, marketing promotion is insufficient. Forest recreation and tourism is a new thing. At present, the propaganda of forest recreation and tourism and Sicilian's existing forest health tourism destinations needs to be strengthened, and the popularity is not high.

\subsection{The rapid rise of the surrounding tourism industry poses a threat to its development}

The threat of developing forest health tourism in Sichuan mainly comes from competition from other provinces and cities. At present, neighboring provinces such as Hunan and Guizhou rely on good forest resources and have proposed to accelerate the development of forest recreation and tourism. Hunan Province proposed to form a forest health industry system integrating tourism, medical care, health care, rehabilitation, health care, education, culture and sports by 2025, and build about 100 forest health care bases with Hunan characteristics in phases. The annual service number reached 30 million, and the comprehensive income reached 100 billion yuan [4]. Guizhou has completed the preparation of forest health planning and standards in the province, relying on the forest tourism brand effect of Yushe, Longjiashan, Baili Dufu National Forest Park and Fanjingshan and Maolan National Nature Reserve, striving to 2020 Guizhou Province has built 100 forest health raising bases, serving 50 million people a year, and built 10 forest health care brands. The surrounding provinces have vigorously developed the competition brought by forest recreation and tourism, forcing Sichuan to combine its own comparative advantages to form characteristics and shape the brand.

\section{Ways to develop migratory bird-style tourism industry in Panxi ethnic areas}

\subsection{Focus on the development of Health and wellness and Health and wellness resources}

First, develop the tourism industry. In combination with the construction of 16 tourist villages and 46 new villages in Panxi area, the fruit is promoted by Datian Pomegranate, Mixed Salon Mango, Total Early Maturity and other high-quality fruit bases, Yisala and other special villages, as well as resources such as Zhiqiu Culture. The combination of special resources such as culture and culture and tourism development, the construction of a cluster of national cultural and Health and wellness tourism products, a cluster of sunny life boutique tourist towns (including characteristic villages), and fruit and leisure leisure bases. The development of Health and wellness resources includes: Sunshine Rural Tourism Product Cluster, Zhiqiu Culture Creative Tourism Product Cluster, Flower and Fruit Tourism Product Cluster. In view of the development of comprehensive tourism resources, it should be noted that the unfavorable factors such as stereotypes and dry heat in the industrial cities of Panxi area have certain adverse effects on the development of the tourism industry. In order to solve the problem of outdoor hot and dry climate in Panxi, we will increase the Health and wellness facilities on the water and enrich the content of the leisure travel service [5].

Second, focus on the development of the Hongge Hot Spring Health Care and Urban Health Care. The hot spring health treatment section is located in Hongge Town and surrounding areas of Yanbian County. Relying on hot springs, resort hotels, characteristic villages, sports training bases, sports schools and other resources, the focus is on promoting the construction of hot springs and 
health, and providing services such as old-age services and tourism. Comprehensive development of agro-industry and business, such as holiday entertainment, business meetings, sports training, etc. The development includes: Hongge Hot Springs and Wellness Tourism Cluster, Sunshine Rural Tourism Cluster, and Flower and Fruit Vegetable Tourism Cluster. The development scope is located in the core area of Panxi area and Renhe District. The development idea is to focus on the construction of Huacheng New District with the theme of Sunshine Flower City, and to complete the comprehensive service functions of the district medical services, old-age health care, recreation and sports, tourism and leisure, etc.

\subsection{Cultivating Health and wellness and tourism professionals is the key}

Talent development is the key to the development of the Health and wellness tourism industry cluster [6-7]. Panxi should firmly establish the concept of tourism professionals, reform the talent introduction and incentive mechanism through innovative talent training methods and models, form a market-oriented, and promote the development of the Panxi Health and wellness tourism industry cluster, in order to cultivate a high level of Health and wellness tourism. Focusing on management talents and urgently needed talents, with the core of improving talent quality and job skills, and aiming at expanding the scale and quality of cluster talents, we will build a talented team with excellent quality, reasonable structure and overall overall efficiency. The development of tourism industry clusters provides inexhaustible driving force.

\subsection{Improve infrastructure construction}

At present, there are only two national-level "Health and wellness" industrial pilot zones in the country, and Panxi is one of them. This shows that the natural resources of the city such as sunshine and forests in Panxi area are unique and irreplaceable in a certain area. How to ensure the maximum use of its natural resources, the city's infrastructure is a prerequisite. The "Health and wellness" industry is aimed not only at Panxi area and surrounding cities, but also for Sichuan and the western part of China. Its external transportation, transit traffic, and traffic within the city area are crucial. Convenient and efficient transportation can greatly enhance the consumer experience of the "Health and wellness" service users, and can increase the attraction of the "Health and wellness" industry to the reachable areas.

\section{Conclusion}

The development of tourism in ethnic areas has a great role in promoting the economic development of ethnic areas, especially in the development of characteristic tourism in ethnic areas. Among them, the "Migratory bird" Health and wellness leisure tourism model has quite a market in ethnic areas. Therefore, local governments should have a strategic vision for development, formulate scientific tourism project development policies, and pay attention to the market supply and demand of "Migratory bird" Health and wellness tourism. Starting from the perspective of supply and demand, we will integrate regional tourism resources, promote large and small, strengthen the weak, focus on brand benefits, build an industrial chain of elderly health tourism services, and develop channelization related industries for the elderly, and strengthen the national pharmaceutical industry such as traditional Chinese medicine and Zhuangyao. Actively promote the construction of old-age towns and old-age industrial parks, encourage the integration of real estate projects and old-age services, and realize the industrialization of "Migratory bird-style" recreation and leisure tourism in the region, inject economic development vitality into the region, and achieve the goal of overall regional common prosperity. 


\section{References}

[1] Sichuan "Research on the Development of Health and wellness Industry", Li Houqiang, Liao Zujun. Ecological Health and wellness Look at Panxi to Create a Concentric Circle Layer Development System with "Six Degrees Theory" as a Metric. Contemporary County Economy, Vol. 2 (2015) No. 4, p. 24 -29.

[2] This journal comprehensive. Panxi Economic Zone "Full creation posture" boosts emerging growth poles . Sichuan Party Building, Vol. 10 (2017) No. 21, p.303-307.

[3] Lai Qihang. Preliminary Study on the Development of Panzhihua Health and wellness Tourism Industry Cluster. Journal of Panzhihua University: Comprehensive Edition, Vol.6(2016) No. 33, p.124-129.

[4] He Wei. Research on the Construction of Well-funded Tourism Towns Based on Demand Orientation. Journal of Beijing Union University (Humanities and Social Sciences), Vol. 2 (2017) No. 15, p.41-47.

[5] Li Qiang. Research on the Positive Interaction between Panzhihua Sunshine Health and wellness Tourism and Real Estate Industry. Journal of Panzhihua University, Vol. 3 (2014) No. 31, p.24-25.

[6] Gao Xiaoru. Research on the Development of Health and wellness Tourism in the Background of Mass Tourism. Travel Overview (The second half of the month), Vol. 12 (2017) No. 31, p.21-27.

[7] Lu Juan. Research on Health and wellness Tourism under the Background of "Popular Tourism". Decision Making and Information, Vol. 6 (2017) No. 12, p.48-50. 